\title{
Dynamics of Legionella Community Interactions in Response to Temperature and Disinfection Treatment: 7 Years of Investigation
}

\author{
Luna Girolamini $^{1}$ (D) Silvano Salaris ${ }^{1}$ (D) $\cdot$ Maria Rosaria Pascale ${ }^{1}$ (D) $\cdot$ Marta Mazzotta $^{1}$ (D) Sandra Cristino $^{1}$ (D)
}

Received: 15 March 2021 / Accepted: 17 May 2021 / Published online: 5 June 2021

(c) The Author(s) 2021

\begin{abstract}
In man-made water distribution systems, Legionella community interactions remain unknown, due to their ability to change from sessile to planktonic states or live in viable but non-culturable forms, in response to anthropic and environmental stress. During 7 years of hospital Legionella surveillance, in 191 hot water positive samples, the interactions among the Legionella species, temperature, and disinfection treatment were evaluated. Legionella was isolated following ISO 11731:2017, and identification was performed by mip gene sequencing and sequence-based typing (SBT) for L. anisa or L. rubrilucens and $L$. pneumophila, respectively. The species with the higher frequency of isolation was L. pneumophila serogroup 1 $(78.53 \% ; 4865.36 \pm 25,479.11 \mathrm{cfu} / \mathrm{L})$, followed by L. anisa $(54.45 \% ; 558.79 \pm 2637.41 \mathrm{cfu} / \mathrm{L})$ and L. rubrilucens $(21.99 \%$; $307.73 \pm 1574.95 \mathrm{cfu} / \mathrm{L}$ ), which were sometimes present together. Spearman's rho correlation test was conducted among the species with respect to temperature and disinfectant $\left(\mathrm{H}_{2} \mathrm{O}_{2} / \mathrm{Ag}^{+}\right)$. The results showed a generally positive interaction among these species sharing the same environment, except for competition between $L$. anisa and $L$. rubrilucens. High temperature $\left(48.83 \pm 2.59^{\circ} \mathrm{C}\right)$ and disinfection treatment $(11.58 \pm 4.99 \mathrm{mg} / \mathrm{L})$ affected the presence of these species. An exception was observed with $L$. anisa, which showed disinfection treatment resistance. For the purposes of environmental surveillance, it is fundamental to better understand the interactions and dynamic of the Legionella community in man-made water systems in order to choose the proper physical or chemical treatments. The simultaneous presence of different Legionella species could result in an increased resistance to high temperature and disinfectant treatment, leading to changes in contamination level and species diversity.
\end{abstract}

Keywords Legionella community $\cdot$ Legionella interaction $\cdot$ Resistance $\cdot$ L. anisa $\cdot$ L. rubrilucens $\cdot$ L. pneumophila

Luna Girolamini and Silvano Salaris contributed equally to this work.

Sandra Cristino

sandra.cristino@unibo.it

Luna Girolamini

luna.girolamini2@unibo.it

Silvano Salaris

silvano.salaris@unibo.it

Maria Rosaria Pascale

mariarosaria.pascal2@unibo.it

Marta Mazzotta

marta.mazzotta2@unibo.it

1 Department of Biological, Geological, and Environmental Sciences, University of Bologna, via San Giacomo 12, 40126 Bologna, BO, Italy

\section{Introduction}

Legionella species are Gram-negative and ubiquitous bacteria that are inhabitants of fresh and artificial water systems and biofilms. The Legionella genus includes up to 60 species [1] and more than 70 different serogroups [2]. Approximately 20 species of Legionella have been proven to be causative agents of Legionnaires' disease (LD). In total, $85 \%$ of human diseases are caused by L. pneumophila ( $L p)$ serogroup 1 ( $L p 1)$ [3]. About $10 \%$ of human infections are caused by non-pneumophila Legionella species (n- $p L)$, especially $L$. micdadei, $L$. bozemanae, $L$. longbeachae, $L$. dumoffii, and $L$. feeleii, which are repeatedly isolated from hospitalized patients, whereas L. anisa, L. wadsworthii, and L. cincinnatiensis are only rarely found $[4,5]$. The differences described could probably be attributed to the specificity and sensitivity of the antigenic urinary diagnostic test for $L p$, and especially $L p 1[2,6]$. 
The temperature is one of the most important factors for the presence and growth of Legionella in environments and pipeline water distribution systems. Legionella can survive for long periods in several natural and artificial environments at fairly high temperatures and in the presence of disinfectants, resisting anthropogenic and environmental stress [7]. Legionella are mesophilic bacteria; they can survive in a temperature ranging from 5.7 to $63{ }^{\circ} \mathrm{C}$, but their optimal growth temperature is between 25 and $40{ }^{\circ} \mathrm{C}$ [8, 9]. For this reason, to decrease the risk of legionellosis, a high temperature (above $50{ }^{\circ} \mathrm{C}$ ) is highly recommended [10-12]. In addition, a wide variety of disinfection techniques, including chemical disinfection (chlorine dioxide, monochloramines, and hydrogen peroxide, etc.) and physical treatments like ultraviolet (UV) light and high temperature (shock treatment), have been employed worldwide as strategies to reduce the risk of legionellosis [13, 14]. Due to the ability of Legionella to survive in cysts of free-living protozoa, such as several ameba species (e.g., Acanthamoeba polyphaga, A. castellani, Vermamoeba vermiformis, or Dictyostelium discoideum), as well as in biofilm aggregates, they can find protection against environmental and anthropic stress (e.g., disinfectants) [15-17]. As previously documented, the disinfection of water distribution systems, as well as changes in environmental conditions (e.g., pH, nutrition levels, and water flow), permits the release of L. pneumophila that is able to alternate between a sessile (biofilm) and a free-living planktonic state [18, 19]. Moreover, the corrosion of the biofilm surface permits bacterial dispersion, increasing the risks of transmission by water contact or aerosolization [20, 21]. In man-made water distribution systems, $L p$ and n- $p L$ can live together or alone [22-26]. It is poorly known if bacteria belonging to Legionella species compete or exhibit commensal interactions in the same environment.

This study aimed to understand the interactions and dynamics of the Legionella community in the hot water distribution system of an Italian hospital, during 7 years of Legionella environmental surveillance. Based on our previous findings [27, 28], the molecular characterization of $L p$ and n- $L p$ species highlighted the presence of a variegated environment and suggested a need to study the complex community found, in order to obtain detailed insights into the community ecology of Legionella species and their responses to temperature and disinfection treatment. Our knowledge of the hospital permitted us to study the interaction between the $L p$ and $n-p L$ populations, and their response to chemical and physical treatments.

\section{Methods}

\section{Hospital Water Safety Plan and Disinfection Treatment}

This study was conducted in an Italian hospital which, according to Italian Guidelines [29], had a water safety plan
(WSP) involving a Legionella surveillance program consisting of hot water distribution system sampling performed four times per year. The characteristics of the risk assessment plan of the hospital have been previously described [27].

Briefly, control of Legionella contamination in the hospital started from 2013. The hospital hot water distribution systems were treated with a disinfectant based on a stabilized combination of hydrogen peroxide $\left(\mathrm{H}_{2} \mathrm{O}_{2}\right)(34 \%$, wt/ wt) and silver $\left(\mathrm{Ag}^{+}\right)$salts $(0.003 \%$, wt $/ w t)\left(\mathrm{H}_{2} \mathrm{O}_{2} / \mathrm{Ag}^{+}\right)$.

\section{Sample Collection}

From 2013 to 2019, 307 hot water samples (2 L) were collected in the post-flushing modality [30]. During sampling, values of temperature and disinfectant residues were measured and recorded at distal outlets.

\section{Microbiological Analysis and Isolate Identification}

The isolation of Legionella from hot water samples was performed by the culture technique according to the ISO 11731:2017. The fixed detection limit was 50 colony-forming units per liter $(\mathrm{cfu} / \mathrm{L})$ [31]. The culture takes a minimum of 10 to up 15 days, and every 2 days, the plates were examined and the presumptive colonies were enumerated and subcultured on BCYE agar with L-cysteine (cys+) and without L-cysteine (cys-) (Thermo Fisher Scientific, Diagnostic, Ltd., Basingstoke, UK). The Legionella colonies' growth was observed only on BCYE agar with L-cysteine (BCYE cys+). These Legionella colonies (at least five different colonies for each plate) were identified using the Legionella latex test kit (Legionella latex test kit; Thermo Fisher Scientific, Ltd. Basingstoke, UK), based on the manufacturer's instructions.

The data obtained were expressed as the mean concentration \pm standard deviation (SD), and colony-forming units/l (cfu/L).

Molecular gold standard techniques for Legionella identification were applied [32, 33]. Briefly, Genomic DNA was extracted from isolates by the InstaGene Purification Matrix (Bio-Rad, Hercules, CA). Gene amplification was carried out in a $50-\mu \mathrm{L}$ reaction volume containing DreamTaq Green PCR Master Mix 2× (Thermo Fisher Scientific) and 40 pmol of each primer, while $100 \mathrm{ng}$ of DNA was used as template. Following purification, DNA was sequenced using BigDye Chemistry and analyzed on an ABI PRISM 3100 Genetic Analyzer (Applied Biosystems, Foster City, CA). All strains identified as L. pneumophila by agglutination tests were analyzed by sequence-based typing (SBT) to determine the sequence type (ST) according to an ELDSNet protocol (http://bioinforatics.phe.org.uk/legionella/ legionella_sbt/php/sbt_homepage.php). ST allelic profile 
was assigned by the ELDSNet database (http://www.hpabi oinformatics.org.uk/cgibin/legionella/sbt/seq_assemble_ legionella1.cgi); strains identified as Legionella species were analyzed by mip sequencing, as described by Ratcliff et al. [34]. The sequences were compared with sequences deposited in the Legionella mip gene database using a similarity analysis tool (http://bioinformatics.phe.org.uk/cgi-bin/legio nella/mip/mip_id.cgi). The identification at the species level was conducted based on $\geq 98 \%$ similarity to a sequence in the database [35].

\section{Statistical Analysis}

Statistical analyses were performed using R Statistical Software (version 4.0.2, "Taking Off Again" R Foundation for Statistical Computing, Vienna, Austria). The Shapiro-Wilk test was performed to study the variables' normality. In order to evaluate whether the samples originated from the same distribution, Mann-Whitney tests were carried out. Spearman's rho rank correlations were calculated for each pairwise combination ( $L p 1, L$. anisa, L. rubrilucens, temperature, and disinfectant) in nine different groups identified to evaluate the interaction among the species.

Spearman's rho coefficient was used to classify the correlation found according to Asuero et al. [36], as follows:

- \pm 0.90 to \pm 1.00 : Very high correlation;

- \pm 0.70 to \pm 0.89 : High correlation;

- \pm 0.50 to \pm 0.69 : Moderate correlation;

- \pm 0.30 to \pm 0.49 : Low correlation;

- 0.00 to \pm 0.29 : Little if any correlation.

The significance of all statistical tests was set at a $p$ value of $(p) \leq 0.05$.

\section{Results}

\section{Physical and Chemical Parameters}

During the study, temperature and disinfectant residues $\left(\mathrm{H}_{2} \mathrm{O}_{2} / \mathrm{Ag}^{+}\right)$were measured for all outlets sampled. The hospital's mean temperature and disinfectant concentration, measured at distal outlets, were $48.83 \pm 2.59{ }^{\circ} \mathrm{C}$ and $11.58 \pm 4.99 \mathrm{mg} / \mathrm{L}$, respectively. In detail, Table 1 shows the physical-chemical parameters measured.

\section{Legionella Community Characteristics}

From 307 hot water samples analyzed for detection and enumeration of Legionella spp., only the positive samples $(191 / 307,62.2 \%)$ were considered for this study.
The Legionella hospital community was represented by three Legionella species: $L p 1$ was isolated in 150/191 samples $(78.53 \% ; 4865.36 \pm 25,479.11 \mathrm{cfu} / \mathrm{L})$ and $\mathrm{n}-p L$ in $124 / 191$ samples $(21.4 \% ; 866.52 \pm 3042.75 \mathrm{cfu} / \mathrm{L})$. In some cases, they were present at the same time, in the same sample.

In particular, regarding the $124 \mathrm{n}-p L$ positive samples, $104 / 124(83.87 \% ; 558.79 \pm 2637.41 \mathrm{cfu} / \mathrm{L})$ belonged to $L$. anisa and $42 / 124(33.87 \% ; 307.73 \pm 1574.95 \mathrm{cfu} / \mathrm{L})$ to $L$. rubrilucens. In some samples, these species were simultaneously present.

\section{Legionella Community Interactions}

A total of 191 Legionella positive samples were examined in order to evaluate the species interactions within the samples.

A comparison between the two main communities, represented by $L p 1$ vs n- $p L$, performed by the Mann-Whitney test, returned a significant difference $(p=0.011)$, with $L p 1$ higher than $\mathrm{n}-p L\left(p=5.67 \times 10^{-3}\right)$.

To study the interaction within the Legionella species found, the following groups were defined:

A. All 191 Legionella positive samples;

B. Samples (n. 67) contaminated by only $L p 1$;

C. Sample (n. 41) contaminated by only n- $p L$ (L. anisa and/ or L. rubrilucens);

D. Samples (n. 33) contaminated by only L. anisa;

E. Samples (n. 5) contaminated by only L. rubrilucens;

F. Samples (n. 3) contaminated by L. anisa and L. rubrilucens, simultaneously;

G. Samples (n. 49) contaminated by $L p 1$ and $L$. anisa;

H. Samples (n. 15) contaminated by $L p 1$ and $L$. rubrilucens;

I. Samples (n. 19) contaminated by $L p 1, L$. anisa, and $L$. rubrilucens, simultaneously.

The Legionella contamination levels, with temperature and disinfectant residues, recorded in the nine groups, are shown in Table 1.

For groups A, C, G, H, and I, the Mann-Whitney test was performed to compare the distribution of Legionella isolates belonging to different species. Groups B, D, and E could not be subjected to the Mann-Whitney statistical test because they contained a single species.

Unfortunately, for group F, statistical analysis was not carried out due to the small sample size (n. 3).

The results obtained comparing the Legionella community concentrations for each group are summarized in Table 2.

In the hospital water distribution system, in groups A, $\mathrm{C}$, and $\mathrm{G}$, the $L p 1$ population showed the highest concentration, with significant differences with respect to $L$. anisa 
Table 1 Data collected for the nine groups: mean Legionella concentration, temperature, and disinfectant residues

\begin{tabular}{|c|c|c|c|c|c|c|c|}
\hline Groups & $\begin{array}{l}\text { Number } \\
\text { of sam- } \\
\text { ples }\end{array}$ & Parameters & $\begin{array}{l}\text { Lp } 1 \text { concentration } \\
(\mathrm{cfu} / \mathrm{L})\end{array}$ & $\begin{array}{l}\text { L. anisa concentration } \\
(\mathrm{cfu} / \mathrm{L})\end{array}$ & $\begin{array}{l}\text { L. rubrilucens concentration } \\
(\mathrm{cfu} / \mathrm{L})\end{array}$ & $\begin{array}{l}\text { Temperature } \\
\left({ }^{\circ} \mathrm{C}\right)\end{array}$ & $\begin{array}{l}\mathrm{H}_{2} \mathrm{O}_{2} \\
(\mathrm{mg} / \mathrm{L})\end{array}$ \\
\hline \multirow[t]{3}{*}{ A } & \multirow[t]{3}{*}{191} & Mean \pm SD & $4865.36 \pm 25,479.11$ & $558.79 \pm 2637.41$ & $307.73 \pm 1574.95$ & $48.83 \pm 2.59$ & $11.58 \pm 4.99$ \\
\hline & & Min-Max & $0-251,400.00$ & $0-29,000.00$ & $0-14,100.00$ & $32.5-54.50$ & $0-25.00$ \\
\hline & & Median & 100.00 & 12.50 & 0 & 49.17 & 10.60 \\
\hline \multirow[t]{3}{*}{$\mathrm{B}$} & \multirow[t]{3}{*}{67} & Mean \pm SD & $3854.08 \pm 21,660.98$ & & & $49.28 \pm 3.05$ & $10.47 \pm 5.35$ \\
\hline & & Min-Max & $8.33-175,250$ & & & $32.50-54.50$ & $0-21.00$ \\
\hline & & Median & 166.67 & & & 49.50 & 10.00 \\
\hline \multirow[t]{3}{*}{$\mathrm{C}$} & \multirow[t]{3}{*}{41} & Mean \pm SD & & $545.34 \pm 946.45$ & $73.65 \pm 390.42$ & $48.81 \pm 2.84$ & $13.32 \pm 5.55$ \\
\hline & & Min-Max & & $0-3250.00$ & $0-2500.00$ & $33.27-51.10$ & $1.50-25.00$ \\
\hline & & Median & & 50.00 & 0 & 49.40 & 13.33 \\
\hline \multirow[t]{3}{*}{$\mathrm{D}$} & \multirow[t]{3}{*}{33} & Mean \pm SD & & $510.87 \pm 874.22$ & & $48.71 \pm 3.04$ & $14.30 \pm 5.21$ \\
\hline & & Min-Max & & $7.14-3250.00$ & & $33.27-51.10$ & $5.00-25.00$ \\
\hline & & Median & & 50.00 & & 49.30 & 14.00 \\
\hline \multirow[t]{3}{*}{$\mathrm{E}$} & \multirow[t]{3}{*}{5} & Mean \pm SD & & & $48.93 \pm 33.49$ & $50.20 \pm 0.51$ & $9.80 \pm 6.68$ \\
\hline & & Min-Max & & & $7.14-100.00$ & $49.60-50.80$ & $1.50-20.00$ \\
\hline & & Median & & & 50.00 & 50.25 & 10.00 \\
\hline \multirow[t]{3}{*}{$\mathrm{F}$} & \multirow[t]{3}{*}{3} & Mean \pm SD & & $1833.33 \pm 1560.72$ & $925.00 \pm 1366.79$ & $47.60 \pm 2.36$ & $8.33 \pm 2.89$ \\
\hline & & Min-Max & & $50.00-2950.00$ & $50.00-2500.00$ & $45.60-50.20$ & $5.00-10.00$ \\
\hline & & Median & & 2500.00 & 225.00 & 47.00 & 10.00 \\
\hline \multirow[t]{3}{*}{$\mathrm{G}$} & \multirow[t]{3}{*}{49} & Mean \pm SD & $4881.40 \pm 22,454.70$ & $1497.32 \pm 5018.80$ & & $48.46 \pm 2.17$ & $11.83 \pm 4.02$ \\
\hline & & Min-Max & $16.67-156,612.50$ & $6.25-29,000.00$ & & $37.83-52.02$ & $4.25-22.50$ \\
\hline & & Median & 312.50 & 100.00 & & 48.45 & 11.67 \\
\hline \multirow[t]{3}{*}{$\mathrm{H}$} & \multirow[t]{3}{*}{15} & Mean \pm SD & $17,313.74 \pm 64,765.97$ & & $2259.57 \pm 4645.71$ & $49.08 \pm 1.00$ & $9.62 \pm 4.05$ \\
\hline & & Min-Max & $11.11-251,400.00$ & & $11.11-14,100.00$ & $47.20-50.50$ & $1.00-16.25$ \\
\hline & & Median & 125.00 & & 75.00 & 49.05 & 10.00 \\
\hline \multirow[t]{3}{*}{ I } & \multirow[t]{3}{*}{19} & Mean \pm SD & $8004.81 \pm 17,781.96$ & $578.99 \pm 665.79$ & $1150.73 \pm 2097.03$ & $48.02 \pm 1.92$ & $12.54 \pm 4.22$ \\
\hline & & Min-Max & $16.67-72,092.86$ & $16.70-2750.00$ & $16.67-8400.00$ & $42.50-50.86$ & $7.50-20.00$ \\
\hline & & Median & 400.00 & 391.67 & 428.57 & 48.47 & 10.33 \\
\hline
\end{tabular}

and $L$. rubrilucens. The lowest contamination was found for L. rubrilucens.

To correlate the Legionella community and the physical-chemical parameters, such as temperature and disinfectant residues, Spearman's rho correlation tests were used for all possible pairwise combinations ( $L p 1, L$. anisa, and L. rubrilucens; temperature; and disinfectant residues).
Table 2 Comparison of distribution of Legionella species within the groups

\begin{tabular}{|c|c|c|c|c|}
\hline Groups & Legionella comparison & $\begin{array}{l}\text { Mann-Whitney test } \\
p \text { value }\end{array}$ & Legionella comparison & $\begin{array}{l}\text { Mann-Whitney test } \\
p \text { value }\end{array}$ \\
\hline \multirow[t]{3}{*}{ A } & $L p 1 \neq L$. anisa & $1.22 \times 10^{-7 *}$ & Lp1>L. anisa & $6.09 \times 10^{-8 *}$ \\
\hline & Lp $1 \neq$ L. rubrilucens & $2.20 \times 10^{-16 *}$ & Lp1>L. rubrilucens & $2.20 \times 10^{-16 *}$ \\
\hline & L. anis $\neq \neq$ L. rubrilucens & $1.04 \times 10^{-9 *}$ & L. anisa $>$ L. rubrilucens & $5.21 \times 10^{-10 *}$ \\
\hline $\mathrm{C}$ & L. anis $a \neq$ L. rubrilucens & $4.76 \times 10^{-9 *}$ & L. anisa $>$ L. rubrilucens & $2.38 \times 10^{-9 *}$ \\
\hline G & $L p 1 \neq L$. anisa & $0.028^{*}$ & Lp $1>$ L. anisa & $0.014^{*}$ \\
\hline $\mathrm{H}$ & Lp $1 \neq$ L. rubrilucens & 0.66 & / & / \\
\hline \multirow[t]{3}{*}{ I } & $L p 1 \neq L$. anisa & 0.47 & / & / \\
\hline & Lp $1 \neq$ L. rubrilucens & 0.57 & / & / \\
\hline & L. anisa $\neq$ L. rubrilucens & 0.80 & / & l \\
\hline
\end{tabular}

$* p \leq 0.05$ 
In Table 3, we show the general correlation found between all 191 positive samples and the two main groups represented by $L$. pneumophila and n- $p L$.

In Table 4, it is possible to assess the correlation within each group represented by samples contaminated by only one species (Lp1 or L. anisa or L. rubrilucens) and their interaction when they are present in multiple combinations in the same sample.

In group A, regarding the Legionella community, we found a negative correlation $(-0.10)$ between $L p 1$ and $L$. anisa, without statistically significance differences. Increasing $L p 1$ led to a decrease in $L$. anisa, or vice versa. By contrast, the correlation within $L p 1$ and $L$. rubrilucens was positive, with a cohabitation of the two species in the same samples, despite the absence of statistically significant differences.

Regarding group $\mathrm{C}$, the correlation between $L$. anisa and $L$. rubrilucens was negative $(-0.25)$, without statistically significant differences. Concerning group G, the correlation between $L p 1$ and $L$. anisa was positive, with statistically significant differences $(0.33, p=0.02)$. Moreover, in group $\mathrm{H}$, the correlation between $L p 1$ and L. rubrilucens was positive and statistically significant $(0.60, p=0.02)$. In conclusion, in group I, the correlation between $L p 1$ and $L$. anisa, as well as $L p 1$ and L. rubrilucens, was positive ( 0.41 and 0.23 , respectively), despite no statistically significant differences. Instead, $L$. anisa and $L$. rubrilucens showed a non-significant negative correlation (-0.02).

The analysis of the correlation between Legionella and the physical-chemical parameters showed interesting results. In group A, a negative correlation was found for all Legionella strains (Lp1, L. anisa, L. rubrilucens) and temperature $(-0.23,-0.28$, and -0.10 , respectively); an increase in temperature led to a decrease in mean Legionella concentration, with significant correlations for $L p 1\left(p=1.7 \times 10^{-3}\right)$ and $L$. anisa $\left(p=1.0 \times 10^{-4}\right)$. The analysis of the effect of the disinfectant concentration on the Legionella community, in group A, showed a positive significant correlation with $L$. anisa $(0.15, p=0.042)$; increasing the disinfectant dosage led to an increase in the $L$. anisa concentration. On the contrary, for $L p 1$ and $L$. rubrilucens, the data showed a non-significant negative correlation $(-0.11$, for both species) with the disinfectant concentration; the disinfectant interfered with the Legionella concentration.

In group B, a negative correlation was observed $(-0.14)$ between $L p 1$ and temperature, although without significant results. Regarding the effect of disinfectant, $L p 1$ showed a non-significant positive correlation (0.11); disinfectant affected the $L p 1$ concentration.

Group C showed a negative correlation $(-0.25)$ between L. anisa and temperature. On the other hand, L. rubrilucens maintained its non-significant positive correlation (0.12).

Regarding the effect of disinfectant on the Legionella community, a positive correlation (0.14) with $L$. anisa was found, without statistically significant differences. In spite of this, the correlation found with $L$. rubrilucens was a significant negative correlation $\left(-0.41, p=7.3 \times 10^{-3}\right)$; an increased disinfectant dosage caused a decrease in the $L$. rubrilucens concentration.

In group $\mathrm{D}$, the correlation between $L$. anisa and temperature showed non-significant negative result $(-0.14)$. Regarding the effect of disinfectant, $L$. anisa showed a nonsignificant positive correlation (0.05). Temperature could interfere with $L$. anisa growth, but disinfectant did not impact $L$. anisa.

In group E, the correlation between L. rubrilucens and temperature showed a non-significant positive result (0.02). The effect of disinfectant on L. rubrilucens showed a nonsignificant negative correlation $(-0.36)$.
Table 3 Correlation between Legionella, temperature, and disinfectant residues between the three macro-groups (A, B and C)

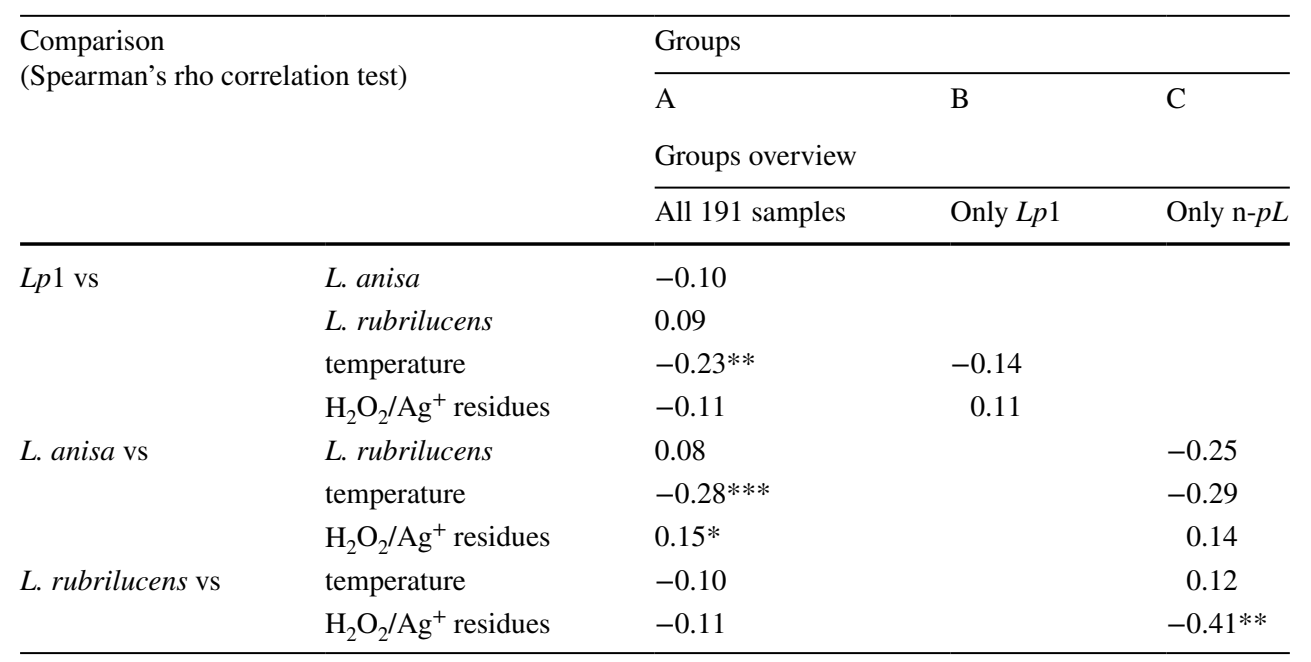

$* p \leq 0.05, * * p \leq 0.01, * * * p \leq 0.001$ 


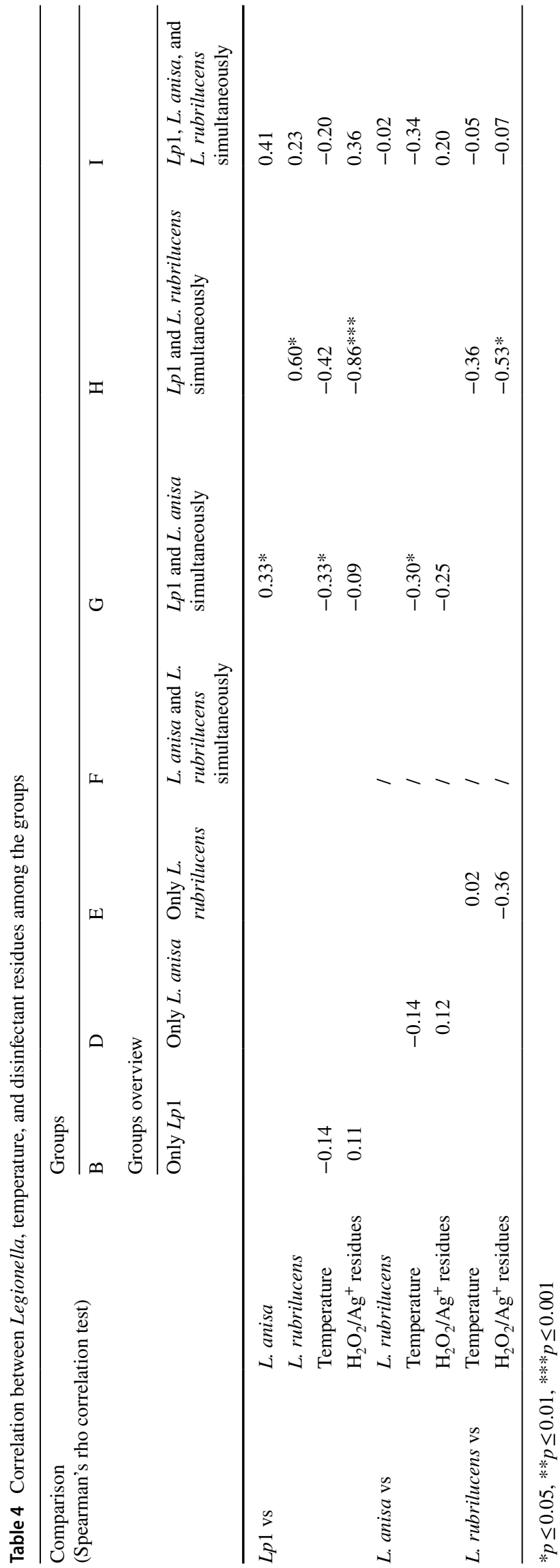

The correlation found in group $\mathrm{G}$ between $L p 1$ and $L$. anis $a$ and temperature showed a significant negative value $(-0.33, p=0.02$ and $-0.30, p=0.04$, respectively). Regarding the effect of disinfectant on Legionella spp., both $L p 1$ and $L$. anisa showed a non-significant negative correlation ( -0.09 and -0.25 , respectively).

Regarding group $\mathrm{H}$, the correlation between $L p 1$ and $L$. rubrilucens with temperature was a non-significant negative correlation ( -0.42 and -0.36 , respectively). The same trend was observed for disinfectant concentration, but with significant result both for $L p 1\left(-0.86, p=1.0 \times 10^{-5}\right)$ and $L$. rubrilucens $(-0.53, p=0.04)$.

The results obtained in group I highlighted a non-significant negative correlation between $L p 1, L$. anisa, and $L$. rubrilucens and temperature $(-0.20,-0.34$, and -0.05 , respectively). Regarding the effect of disinfectant on Legionella, a non-significant positive correlation with $L p 1$ and $L$. anisa was found ( 0.36 and 0.20 , respectively). The disinfectant residues and $L$. rubrilucens showed a negative correlation $(-0.07)$.

\section{Discussion}

Our research aimed to study the ecology of the Legionella community in a hospital distribution system, using data regarding Legionella contamination recorded over 7 years of environmental surveillance. The data presented in our previous studies $[27,28]$ regarding Legionella contamination, its modulation over the year, and the variety of populations found in the hospital suggested the need for a study of correlations among the Legionella community and the interaction of Legionella species with physical and chemical parameters.

In 7 years of Legionella surveillance, the hospital was colonized by $L p 1$ and two species of $\mathrm{n}-p L$ : $L$. anisa and $L$. rubrilucens, with changes in the level of contamination over time.

Starting from general contamination data, the strain with a higher frequency of isolation was $L p 1$ (78.53\%), followed by L. anisa (54.45\%) and L. rubrilucens (21.99\%). In some cases, they were present at the same time in the same sample. Understanding the relationship of the Legionella community and its interactions with physical and chemical parameters could contribute to explaining the dynamic of contamination in a complex water distribution system, such as the hospital environment.

Although several studies have reported the presence of different species of Legionella in the same samples during environmental surveillance, few have referred to the interaction between the most common, L. pneumophila, and less documented species, $L$. anisa and $L$. rubrilucens, in the environment, as well as in clinical samples [26-28, 37, 38]. 
As widely documented by epidemiological data, $L p 1$ is the major causative agent of legionellosis [3]; L. anisa is often linked to single cases or epidemic events $[39,40]$. The knowledge about etiology, as well as pathogenicity, of $L$. rubrilucens is less than that of $L p 1$ and $L$. anisa, with few clinical cases reported [38, 41]. Few studies have reported human coinfection by $L$. pneumophila with $L$. anisa or $L$. pneumophila with $L$. rubrilucens $[38,42]$. Poor knowledge is also reported in environments where the bacteria community is influenced by other bacteria, water, and pipeline features. For this reason, the study of interactions among these species is necessary.

Based on our results, the Legionella community had different outcomes. The analysis of correlations among all samples, as presented in group A, showed a negative correlation between $L p 1$ and $L$. anisa that was not observed in other groups. The increase in one of the two species leads to a decrease in the other one, displaying an antagonistic relationship, as previously described by Van Der Mee-Marquet et al. [26]. On the other hand, $L p 1$ was not affected by the presence of other species, such as L. rubrilucens, as these two Legionella species seem to live in the same ecological niche without interfering with one another. Instead, a positive correlation between $L$. anisa and L. rubrilucens was observed only in group A; therefore, the two species may be cohabitants of the same environment in a symbiotic relationship. In other groups, a negative correlation was evident, with a score that was low to intermediate.

Regarding the correlation of Legionella with the physical parameters measured, our data confirmed the positive effect of temperature on Legionella control [10, 11, 43]. The maximum mean temperature recorded in the hospital outlets was $54.5^{\circ} \mathrm{C}\left(48.83 \pm 2.59{ }^{\circ} \mathrm{C}\right)$; this is able to control both $L p 1$ and $L$. anisa. These species suffered with increasing temperature, as demonstrated by the negative correlations found in all groups. The results displayed significant differences in $2 / 5$ groups for $L p 1\left(p_{\text {GROUP } A}=0.002\right.$ and $\left.p_{\text {GROUP }}=0.02\right)$, and in $2 / 5$ groups for $L$. anisa $\left(p_{\text {GROUP A }}=1.0 \times 10^{-4}\right.$ and $\left.p_{\text {GROUP G }}=0.039\right)$. L. rubrilucens showed a little/low correlation with temperature, and only group $\mathrm{H}$ showed a medium degree coefficient correlation $(-0.36)$ that could have been associated with a resistance to high temperature. This observation, together with the low concentration of $L$. rubrilucens found in the samples, could explain the thermo-tolerant effect of temperature among Legionella, as demonstrated for L. pneumophila which are able to change into viable, but non-cultivable, forms [44]. Moreover, resistance to temperature seems to be acquired by members of the genus Legionella within species and at the genus level by inter- and intra-species, through spontaneous mutations or horizontal gene transfer [45-47].

Given that the eradication of Legionella is difficult, especially when water system colonization occurs, the simultaneous action of high temperature and disinfection treatment is a valid strategy to control Legionella colonization [17].

As reported in our previous study [27], $\mathrm{H}_{2} \mathrm{O}_{2} / \mathrm{Ag}^{+}$presents economic and operative advantages as disinfection treatment, with good performance in continuous hospital disinfection treatment. Changes occurred, during the study, in the concentration and Legionella species isolated, suggesting a possible role or interaction between Legionella and the disinfectant that could only be investigated by studying their correlation.

Lp1 was generally affected by $\mathrm{H}_{2} \mathrm{O}_{2} / \mathrm{Ag}^{+}$, with statistically significant results $\left(p_{\text {GROUP } \mathrm{H}}=1.0 \times 10^{-5}\right.$ and a high degree of coefficient correlation, -0.86). L. anisa showed a probable resistance to $\mathrm{H}_{2} \mathrm{O}_{2} / \mathrm{Ag}^{+}$treatment, with significant results found in group A $\left(p_{\text {GROUP A }}=0.042\right)$. L. rubrilucens was always sensitive to $\mathrm{H}_{2} \mathrm{O}_{2} / \mathrm{Ag}^{+}$treatment, with significant results $\left(p_{\text {GROUP C }}=0.0073\right.$ and $p_{\text {GROUP H }}=0.042$ ). These varied results for different Legionella species could be explained considering that the continuous dosage of disinfectant recorded in the hospital had a concentration of $11.58 \pm 4.99 \mathrm{mg} / \mathrm{L}$, which was probably too low to achieve good control of the Legionella community. Casini et al. [19], for example, suggest that the dosage to control Legionella contamination in the hospital should be $25 \mathrm{mg} / \mathrm{L}$. Moreover, the presence of catalase or peroxidase in Legionella spp. can increase tolerance to $\mathrm{H}_{2} \mathrm{O}_{2}$ at low concentrations [48, 49]. An increase in dosage could improve the action of $\mathrm{H}_{2} \mathrm{O}_{2} / \mathrm{Ag}^{+}$on all Legionella communities, especially L. pneumophila and $L$. anisa, which seem be more resistant to treatment with respect to L. rubrilucens. We must consider that, when the treatment is performed over time, as in the hospital investigated in this study, it is possible to find persistence and an increase in the concentration of these species. Furthermore, the different and selective activity of $\mathrm{H}_{2} \mathrm{O}_{2} / \mathrm{Ag}^{+}$ on Legionella species could be investigated and explained by the presence of superoxide dismutase activity (SOD), used by Gram-negative bacteria, as well as Legionella. For example, in L. pneumophila, periplasmic SODs of copper and zinc (CuZnSOD) contribute to survival during the stationary phase of growth, and can enhance bacteria pathogenicity [50]. Consequently, the existence of $\mathrm{CuZn-}$ SOD in L. pneumophila could be one of the reasons for its survival despite the disinfection treatment. Unfortunately, there is no evidence regarding the presence or activity of this system in other Legionella species.

A study of the "in vitro" response to the $\mathrm{H}_{2} \mathrm{O}_{2} / \mathrm{Ag}^{+}$ compound used in this hospital could contribute to clarifying the different responses by the species analyzed.

This study, as far as we know, is the first to evaluate the interaction between three different Legionella species, and their interaction with temperature and disinfection treatment, in the same water distribution system. This study 
demonstrated how the presence of one species or more, in the same environment, could contribute to enhancing the growth of species concentration, resistance to disinfectant, or sensitivity to temperature increases.

At the same time, this study raises a new consideration regarding the complexity of the Legionella community, which needs to be investigated further, including giving more attention to lesser known Legionella species. In conclusion, the aquatic environment is a natural reservoir for several bacteria (pathogenic and non-pathogenic) that live in symbiosis or in competition.

Understanding the interaction between the Legionella community and the aquatic environment is valuable not only to obtain and program the right strategies to control these bacteria (e.g., temperature values or disinfectant concentrations), but also to support us to better understand the changes in Legionella communities that occur during extensive disinfection treatment. The surveillance of Legionellosis must consider not only the bacteria concentration, but also the identification of bacterial communities that are influenced by interactions with the environment, water characteristics, and the choice of pipeline system.

Acknowledgements The authors would like to thank Graziella Ciani for the microbiological analysis.

Author Contribution Conceptualization, Luna Girolamini; methodology, Luna Girolamini and Sandra Cristino; software, Luna Girolamini and Silvano Salaris; formal analysis, Maria Rosaria Pascale and Marta Mazzotta; data curation, Luna Girolamini and Silvano Salaris; writing — original draft preparation, review and editing, Luna Girolamini, Sandra Cristino and Silvano Salaris; supervision, Sandra Cristino; project administration, Sandra Cristino. All authors have read and agreed to the published version of the manuscript.

Funding Open access funding provided by Alma Mater Studiorum Università di Bologna within the CRUI-CARE Agreement.

Data Availability Not applicable.

Code Availability Not applicable.

\section{Declarations}

Ethics Approval Not applicable.

Consent to Participate Not applicable.

Consent for Publication Not applicable.

Conflict of Interest Not applicable.

Open Access This article is licensed under a Creative Commons Attribution 4.0 International License, which permits use, sharing, adaptation, distribution and reproduction in any medium or format, as long as you give appropriate credit to the original author(s) and the source, provide a link to the Creative Commons licence, and indicate if changes were made. The images or other third party material in this article are included in the article's Creative Commons licence, unless indicated otherwise in a credit line to the material. If material is not included in the article's Creative Commons licence and your intended use is not permitted by statutory regulation or exceeds the permitted use, you will need to obtain permission directly from the copyright holder. To view a copy of this licence, visit http://creativecommons.org/licenses/by/4.0/.

\section{References}

1. LPSN Bacterio.net List of prokaryotic names with standing in nomenclature Legionella. https://www.bacterio.net/genus/legio nella

2. Fields BS, Benson RF, Besser RE (2002) Legionella and legionnaires' disease: 25 years of investigation. J Clin Microbiol 15:506-526. https://doi.org/10.1128/CMR.15.3.506

3. ECDC (2018) European Centre for Disease Prevention and Control. (2020) legionnaires' disease. In, ECDC. Annual epidemiological report for

4. Yu VL, Plouffe JF, Pastoris MC et al (2002) Distribution of Legionella species and serogroups isolated by culture in patients with sporadic community-acquired legionellosis: an international collaborative survey. J Infect Dis 186:127-128. https://doi.org/10. 1086/341087

5. Beauté J, Robesyn E (2017) European Centre for Disease Prevention and Control - Legionnaires' disease in Europe 2015

6. Svarrer CW, Lück C, Elverdal PL, Uldum SA (2012) Immunochromatic kits Xpect Legionella and BinaxNOW Legionella for detection of Legionella pneumophila urinary antigen have low sensitivities for the diagnosis of legionnaires' disease. J Med Microbiol 61:213-217. https://doi.org/10.1099/jmm.0.035014-0

7. Dupuy M, Mazoua S, Berne F et al (2011) Efficiency of water disinfectants against Legionella pneumophila and Acanthamoeba. Water Res 45:1087-1094. https://doi.org/10.1016/j.watres.2010. 10.025

8. Fliermans CB, Cherry WB, Orrison LH et al (1981) Ecological distribution of Legionella pneumophila. Appl Environ Microbiol 41:9-16

9. Ohno A, Kato N, Yamada K, Yamaguchi K (2003) Factors influencing survival of Legionella pneumophila serotype 1 in hot spring water and tap water. Appl Environ Microbiol Env Microbiol 69:2540-2547. https://doi.org/10.1128/AEM.69.5.2540

10. Serrano-Suárez A, Dellundé J, Salvadó H et al (2013) Microbial and physicochemical parameters associated with Legionella contamination in hot water recirculation systems. Environ Sci Pollut Res 20:5534-5544. https://doi.org/10.1007/s11356-013-1557-5

11. Bonetta S, Bonetta S, Ferretti E et al (2010) Evaluation of Legionella pneumophila contamination in Italian hotel water systems by quantitative real-time PCR and culture methods. J Appl Microbiol 108:1576-1583. https://doi.org/10.1111/j.1365-2672. 2009.04553.x

12. Rasheduzzaman M, Singh R, Haas CN, Gurian PL (2020) Required water temperature in hotel plumbing to control Legionella growth. Water Res 182:115943. https://doi.org/10. 1016/j.watres.2020.115943

13. Blanc DS, Carrara P, Zanetti G, Francioli P (2005) Water disinfection with ozone, copper and silver ions, and temperature increase to control Legionella: seven years of experience in a university teaching hospital. J Hosp Infect 60:69-72. https://doi.org/10. 1016/j.jhin.2004.10.016

14. Canals O, Serrano-Suárez A, Salvadó H et al (2015) Effect of chlorine and temperature on free-living protozoa in operational man-made water systems (cooling towers and hot sanitary water 
systems) in Catalonia. Environ Sci Pollut Res 22:6610-6618. https://doi.org/10.1007/s11356-014-3839-y

15. Barker J, Scaife H, Brown MRW (1995) Intraphagocytic growth induces an antibiotic-resistant phenotype of Legionella pneumophila. Antimicrob Agents Chemother 39:2684-2688. https:// doi.org/10.1128/AAC.39.12.2684

16. Nwachuku N, Gerba CP (2004) Health effects of Acanthamoeba spp. and its potential for waterborne transmission. Rev Environ Contam Toxicol 180:93-131. https://doi.org/10. 1007/0-387-21729-0_2

17. Storey MV, Ashbolt J, Stenström TA (2004) Biofilms, thermophilic amoebae and Legionella pneumophila-a quantitative risk assessment for distributed water. Water Sci Technol 50:77-82

18. García MT, Jones S, Pelaz C et al (2007) Acanthamoeba polyphaga resuscitates viable non-culturable Legionella pneumophila after disinfection. Environ Microbiol 9:1267-1277. https:// doi.org/10.1111/j.1462-2920.2007.01245.x

19. Casini B, Aquino F, Totaro M et al (2017) Application of hydrogen peroxide as an innovative method of treatment for Legionella control in a hospitalwater network. Pathogens 6:112. https://doi.org/10.3390/pathogens6020015

20. Gamage SD, Ambrose M, Kralovic SM, Roselle GA (2016) Water safety and Legionella in health care: priorities, policy, and practice. Infect Dis Clin N Am 30:689-712. https://doi.org/ 10.1016/j.idc.2016.04.004

21. Kaplan JB (2010) Biofilm dispersal: mechanisms, clinical implications, and potential therapeutic uses. J Dent Res 89:205-218. https://doi.org/10.1177/0022034509359403

22. Bédard E, Paranjape K, Lalancette C et al (2019) Legionella pneumophila levels and sequence-type distribution in hospital hot water samples from faucets to connecting pipes. Water Res 156:277-286. https://doi.org/10.1016/j.watres.2019.03.019

23. Lee HK, Shim JI, Kim HE et al (2010) Distribution of Legionella species from environmental water sources of public facilities and genetic diversity of $L$. pneumophila serogroup 1 in South Korea. Appl Environ Microbiol 76:6547-6554. https:// doi.org/10.1128/AEM.00422-10

24. Papadakis A, Chochlakis D, Sandalakis V et al (2018) Legionella spp. risk assessment in recreational and garden areas of hotels. Int J Environ Res Public Health 15:1-15. https://doi. org/10.3390/ijerph15040598

25. Fleres G, Couto N, Lokate M et al (2018) Detection of Legionella anisa in water from hospital dental chair units and molecular characterization by whole-genome sequencing. Microorganisms 6:71. https://doi.org/10.3390/microorganisms6 030071

26. Van Der Mee-Marquet N, Domelier AS, Arnault L et al (2006) Legionella anisa, a possible indicator of water contamination by Legionella pneumophila. J Clin Microbiol 44:56-59. https:// doi.org/10.1128/JCM.44.1.56-59.2006

27. Girolamini L, Dormi A, Pellati T et al (2019) Advances in Legionella control by a new formulation of hydrogen peroxide and silver salts in a hospital hot water network. Pathogens 8:1-21. https://doi.org/10.3390/pathogens8040209

28. Girolamini L, Salaris S, Lizzadro J et al (2020) How molecular typing can support Legionella environmental surveillance in hot water distribution systems: a hospital experience. Int J Environ Res Public Health 17:1-17. https://doi.org/10.3390/ijerph1722 8662
29. Italian Health Ministry (2015) Guidelines for prevention and control of legionellosis. Approvate in Conferenza Stato-Regioni Seduta Del 7 Maggio 2015. Italy, 2015

30. (2006) UNI EN ISO 19458:2006 - Water quality — sampling for microbiological analysis. http://store.uni.com/catalogo/index. php/uni-en-iso-19458-2006.html?josso_back_to=http://store. uni.com/josso-security-check.php\&josso_cmd=login_optio nal\&josso_partnerapp_host=store.uni.com

31. (2017) ISO 11731:2017 Water quality - enumeration of Legionella. https://www.iso.org/standard/61782.html

32. Ratzow S, Gaia V, Helbig JH et al (2007) Addition of neuA, the gene encoding $\mathrm{N}$-acylneuraminate cytidylyl transferase, increases the discriminatory ability of the consensus sequencebased scheme for typing Legionella pneumophila serogroup 1 strains. J Clin Microbiol 45:1965-1968. https://doi.org/10.1128/ JCM.00261-07

33. Mentasti M, Fry NK, Afshar B et al (2012) Application of Legionella pneumophila-specific quantitative real-time PCR combined with direct amplification and sequence-based typing in the diagnosis and epidemiological investigation of legionnaires' disease. Eur J Clin Microbiol Infect Dis 31:2017-2028. https://doi.org/10.1007/s10096-011-1535-0

34. Ratcliff RM, Lanser JA, Manning PA, Heuzenroeder MW (1998) Sequence-based classification scheme for the genus Legionella targeting the mip gene. J Clin Microbiol 36:1560-1567. https:// doi.org/10.1128/jcm.36.6.1560-1567.1998

35. Fry NK, Afshar B, Bellamy W et al (2007) Identification of Legionella spp. by 19 European reference laboratories: results of the European working Group for Legionella Infections External Quality Assessment Scheme using DNA sequencing of the macrophage infectivity potentiator gene and dedi. Clin Microbiol Infect 13:1119-1124. https://doi.org/10.1111/j.1469-0691. 2007.01808.x

36. Asuero AG, Sayago A, González AG (2006) The correlation coefficient: an overview. Crit Rev Anal Chem 36:41-59. https:// doi.org/10.1080/10408340500526766

37. Sydnor ERM, Bova G, Gimburg A et al (2012) Electronic-eye faucets: Legionella species contamination in healthcare settings. Infect Control Hosp Epidemiol 33:235-240. https://doi.org/10. 1086/664047

38. Matsui M, Fujii SI, Shiroiwa R et al (2010) Isolation of Legionella rubrilucens from a pneumonia patient co-infected with Legionella pneumophila. J Med Microbiol 59:1242-1246. https://doi.org/10.1099/jmm.0.016089-0

39. Vaccaro L, Izquierdo F, Magnet A et al (2016) First case of legionnaire's disease caused by Legionella anisa in Spain and the limitations on the diagnosis of Legionella non-pneumophila infections. PLoS One 11:1-12. https://doi.org/10.1371/journal. pone. 0159726

40. Head BM, Trajtman A, Bernard K et al (2019) Legionella coinfection in HIV-associated pneumonia. Diagn Microbiol Infect Dis 95:71-76. https://doi.org/10.1016/j.diagmicrobio.2019.03. 005

41. Amemura-maekawa J, Kura F, Chida K et al (2018) Legionella pneumophila and other Legionella species isolated from legionellosis patients in Japan between 2008 and 2016. Appl Environ Microbiol 84:1-9

42. Berger P, Papazian L, Drancourt M et al (2006) Ameba-associated microorganisms and diagnosis of nosocomial pneumonia. 
Emerg Infect Dis 12:248-255. https://doi.org/10.3201/eid1202. 050434

43. European Working Group for Legionella Infections (ESGLI) (2017) European technical guidelines for the Prevention, Control and Investigation, of Infections Caused by Legionella species

44. Totaro M, Costa AL, Frendo L et al (2020) Evaluation of Legionella spp. colonization in residential buildings having solar thermal system for hot water production. Int J Environ Res Public Health 17:1-8. https://doi.org/10.3390/ijerph1719 7050

45. Gomez-Valero L, Rusniok C, Jarraud S, et al (2011) Extensive recombination events and horizontal gene transfer shaped the Legionella pneumophila genomes. BMC Genomics 12:. https:// doi.org/10.1186/1471-2164-12-536

46. Gomez-Valero L, Rusniok C, Rolando M et al (2014) Comparative analyses of Legionella species identifies genetic features of strains causing legionnaires' disease. Genome Biol 15:1-21. https://doi.org/10.1186/s13059-014-0505-0

47. Lesnik R, Brettar I, Höfle MG (2016) Legionella species diversity and dynamics from surface reservoir to tap water: from cold adaptation to thermophily. ISME J 10:1064-1080. https://doi. org/10.1038/ismej.2015.199

48. McDonnell G, Russell D (1999) Antiseptics and disinfectants: activity, action, and resistance. Am Soc Microbiol 12:147-179

49. Bartram J, Chartier Y, Lee JV et al (2007) Legionella and the prevention of legionellosis. Emerg infect dis 14:1006a - 1006. https://doi.org/10.3201/eid1406.080345

50. St. John G, Steinman HM (1996) Periplasmic copper-zinc superoxide dismutase of Legionella pneumophila: role in stationaryphase survival. J Bacteriol 178:1578-1584. https://doi.org/10. 1128/jb.178.6.1578-1584.1996 